University of Montana

ScholarWorks at University of Montana

$7-2005$

\title{
Unpalatable Plants Protect Neighbors from Grazing and Increase Plant Community Diversity
}

\author{
Ragan M. Callaway \\ University of Montana - Missoula, Ray.Callaway@mso.umt.edu \\ David Kikodze \\ Marina Chiboshvili \\ Liana Khetsuriani
}

Follow this and additional works at: https://scholarworks.umt.edu/biosci_pubs

Part of the Biology Commons

Let us know how access to this document benefits you.

\section{Recommended Citation}

Callaway, Ragan M.; Kikodze, David; Chiboshvili, Marina; and Khetsuriani, Liana, "Unpalatable Plants Protect Neighbors from Grazing and Increase Plant Community Diversity" (2005). Biological Sciences Faculty Publications. 303.

https://scholarworks.umt.edu/biosci_pubs/303

This Article is brought to you for free and open access by the Biological Sciences at ScholarWorks at University of Montana. It has been accepted for inclusion in Biological Sciences Faculty Publications by an authorized administrator of ScholarWorks at University of Montana. For more information, please contact scholarworks@mso.umt.edu. 


\title{
UNPALATABLE PLANTS PROTECT NEIGHBORS FROM GRAZING AND INCREASE PLANT COMMUNITY DIVERSITY
}

\author{
Ragan M. Callaway, ${ }^{1,3}$ David Kikodze, ${ }^{2}$ Marina Chiboshvili, ${ }^{2}$ and Liana Khetsuriani ${ }^{2}$ \\ ${ }^{1}$ Division of Biological Sciences, University of Montana, Missoula, Montana 59812 USA \\ ${ }^{2}$ Institute of Botany of the Georgian Academy of Sciences, 1 Kojori Road, 380007, Tbilisi, Georgia
}

\begin{abstract}
Tasty plants can be protected from herbivores by unpalatable neighbors. We used experimental exclosures, removal of unpalatable species, and transplants of palatable and unpalatable species in subalpine meadows of the Caucasus Mountains of Georgia to study the effects of two unpalatable species on plant communities. We found that Cirsium obalatum and Veratrum lobelianum, two large native perennial herbs that invade after heavy grazing, had strong facilitative effects on communities through their indirect effects on livestock herbivores. These unpalatable invaders had different effects on community composition when livestock were present than when livestock were excluded. Furthermore, removing Cirsium and Veratrum where herbivory was permitted decreased the richness of associated communities, but inside a livestock exclosure removal of these species increased community richness. Transplanted palatable species (Anthoxanthum odoratum and Phleum alpinum) grew larger inside the exclosure, and in the exclosure Cirsium and Veratrum had no effect on their growth. However, outside of the exclosure, Cirsium and Veratrum had strong positive effects on the growth of $A$. odoratum and $P$. alpinum. Excluding livestock decreased the growth of Luzula pseudosudetica, another unpalatable species, and Cirsium and Veratrum had no effect on L. pseudosudetica outside the exclosure. In contrast, inside exclosures Cirsium and Veratrum had competitive effects on L. pseudosudetica. Our results indicate that Cirsium and Veratrum, which are in some ways undesirable rangeland weeds, may also play an important role in maintaining species and functional diversity of overgrazed plant communities in the Caucasus.
\end{abstract}

Key words: Caucasus; Cirsium obalatum; competition; diversity; exclosure; facilitation; increaser; indirect interaction; herbivory; plant community; rangeland; Veratrum lobelianum.

\section{INTRODUCTION}

Palatable species may avoid being eaten by associating with unpalatable neighbors. In an early review, Attsat and O'Dowd (1976) argued that many plant species were "functionally interdependent with respect to their herbivores." They described "defense guilds" in which some members of the plant community functioned as anti-herbivore beneficiaries for other species in three major ways: (1) as hosts for insect predators that attack the herbivores of neighboring plants, (2) as repellent neighbors that make it difficult for herbivores to locate or reject their prey, and (3) as "attractantdecoy" neighbors that attract herbivores to themselves so that they leave the beneficiary alone. As an early example of the repellent neighbor phenomenon, McNaughton (1978) demonstrated that mortality rates of the highly palatable grass Themeda triandra decreased as the abundance of associated unpalatable species increased. Since then, many other studies have documented this indirect form of facilitation, functioning mechanistically as species protecting their neighbors

Manuscript received 10 May 2004; revised 1 November 2004; accepted 22 November 2004. Corresponding Editor: S. W. Seagle.

${ }^{3}$ E-mail: ray.callaway@mso.umt.edu from herbivores (Rausher 1981, McAuliffe 1986, Brown and Ewel 1987, Callaway 1992, Olff et al. 1999, Hambäck et al. 2000, Milchunas and Noy-Meir 2002).

Although indirect interactions mediated by herbivores are well documented, their effects on the composition, structure, and diversity of whole plant communities have received much less attention. To our knowledge only one experimental study has examined the indirect effects of herbivores at the scale of whole plant communities. Rebollo et al. (2002) found that the cactus, Opuntia polycantha, can structure plant communities in the shortgrass steppe of Colorado when cattle grazing is intense. Although experimental evidence is scant, the published observations of many ecologists suggest that the positive effects of unpalatable plants on community composition can be strong when consumer pressure is strong (Clements 1934, Canfield 1948, Weaver and Albertson 1956, McPherson and Wright 1990).

In subalpine meadows of the central Caucasus, extensive overgrazing by sheep during the Soviet era coincided with dramatic increases in the abundance of two unpalatable invaders, Cirsium obalatum and Veratrum lobelianum (Callaway et al. 2000). These species are not exotic, but invaders sensu those species that increase disproportionately in rangelands when 
grazing is intense (Sims and Risser 2000). Cirsium and Veratrum are avoided by livestock because they have spines and toxins, respectively, and because they are much larger than other meadow species and their canopies can cover many individuals of the other smaller species. Plant communities correlated with these unpalatable species are very different in composition than in the open spaces between the invaders (Callaway et al. 2000). Almost half of the other species in the space occupied by Cirsium and Veratrum occurred only with the invaders or at "trace" cover values in the open meadow and at significantly higher covers under Cirsium or Veratrum. These indirect effects do not appear to be geographically consistent because Schaffner et al. (2001) found that Veratrum album was not associated with particular communities in the Alps of Switzerland. Overall, the patterns measured in the Caucasus suggest that unpalatable plants, which are generally considered to be indicators of unhealthy rangelands, have the potential to preserve plant diversity when grazing is exceptionally intense. However, no previous research has experimentally separated abiotic microsite effects from the effects of unpalatable species such as Cirsium and Veratrum. Here, we report on the results of a three-year experiment with herbivore exclosures and invader removals. Our fundamental goal was to determine the effects of the unpalatable rangeland invaders, Cirsium obalatum and Veratrum lobelianum, on the community structure of subalpine meadows in the central Caucasus Mountains.

\section{METHODS}

We took two approaches toward measuring the indirect effects of Cirsium and Veratrum on their neighbors. Both approaches entailed establishing exclosures and experimental removal of the invaders, but the first focused on the response of whole communities to manipulation of herbivores and neighbors, and the other focused on the response of transplanted target species. These approaches were intended to qualitatively support each other. Detailed information on the plant communities, descriptive relationships between other plant species and Cirsium and Veratrum, and the site can be found in Callaway et al. (2000). Herbivores in this system are cattle, sheep, and horses. In the spring of 2001, we established two $2500-\mathrm{m}^{2}$ fenced livestock exclosures using barbed wire fence. Exclosures were $\sim 5$ $\mathrm{km}$ apart in the Jvari Pass region $\left(42^{\circ} 40^{\prime} \mathrm{N}, 44^{\circ} 30^{\prime} \mathrm{E}\right.$ ) of the Caucasus Mountains of Georgia in order to study the effects of Cirsium and Veratrum with and without the effects of herbivory. In the fall of 2001 we clipped $100.25-\mathrm{m}^{2}$ plots inside and outside of each exclosure to estimate grazing intensity in the system. Inside the exclosure, biomass was $177 \pm 38.3 \mathrm{~g} / \mathrm{m}^{2}$ vs. $24 \pm 8.3$ $\mathrm{g} / \mathrm{m}^{2}$ outside of the exclosures. At one exclosure, Jvari, we studied whole-community responses, and at the other exclosure, Gudauri, we studied the responses of experimental transplants. Our intent for using the two sites, both highly invaded by Cirsium and Veratrum, was to provide qualitative generality to our findings. If these invaders are important indirect facilitators in the system, then the positive effects of Cirsium and Veratrum would be strong outside of the exclosures, but attenuate or even switch to competitive effects within the exclosures where livestock herbivory did not occur.

Within the exclosure at Jvari, we randomly selected 50 Cirsium individuals, 50 Veratrum individuals, and 50 sites in the "open" grassland where no Cirsium or Veratrum occurred, as locations for permanent plots in which we measured whole community responses. Open treatments were located haphazardly, but between 0.5 and $1.0 \mathrm{~m}$ from the nearest Cirsium or Veratrum. Of the 100 unpalatable individuals we randomly chose 30 of each species for removal by cutting the plant at the base. Most of these plants died when cut, but any regrowth was cut through each growing season. Another 50 Cirsium individuals, 50 Veratrum individuals, and 50 open sites were chosen outside of the exclosure for permanent plots. These 150 permanent sites were located on all sides of the exclosure to minimize site effects and up to $50 \mathrm{~m}$ from the sides of exclosures. At all 300 sites we established permanent $0.5 \times 0.5 \mathrm{~m}$ quadrats driving metal stakes into the ground at each corner. Before removal of the unpalatable plants in May 2001 , we measured the abundance of all species in all sites by categorizing visual estimates of cover into the seven Braun-Blanquet cover classes used in traditional relevé vegetation analysis (Barbour et al. 1999). After the experimental treatments were applied we measured the changes in abundance of species, three growing seasons later, in the late summer of 2003 using the same cover classes. We compared treatment effects using detrended correspondence analysis in the software package PC-ORD (McCune and Mefford 1997). Ordination scores were compared simply using the degree of overlap between $95 \%$ confidence intervals calculated and graphed in SigmaPlot (SPSS 2001) and the means of different treatments.

If Cirsium and Veratrum are important facilitators of more palatable species in these subalpine communities, we predicted several responses to our treatments. First, palatable species should increase in abundance and productivity in the open (away from Cirsium and Veratrum) inside of exclosures, but not outside of exclosures. Second, removal of Cirsium and Veratrum outside of exclosures should result in a decrease in the abundance and productivity of palatable species (relative to initial measurements and the control, non-removed Cirsium and Veratrum), but this decrease should not occur inside of exclosures.

At the Gudauri site, we transplanted 12 individuals of each of the four different species into each experimental treatment (in the open, under Cirsium and Veratrum, and where Cirsium and Veratrum had been removed) both inside and outside exclosures (total $n$ 


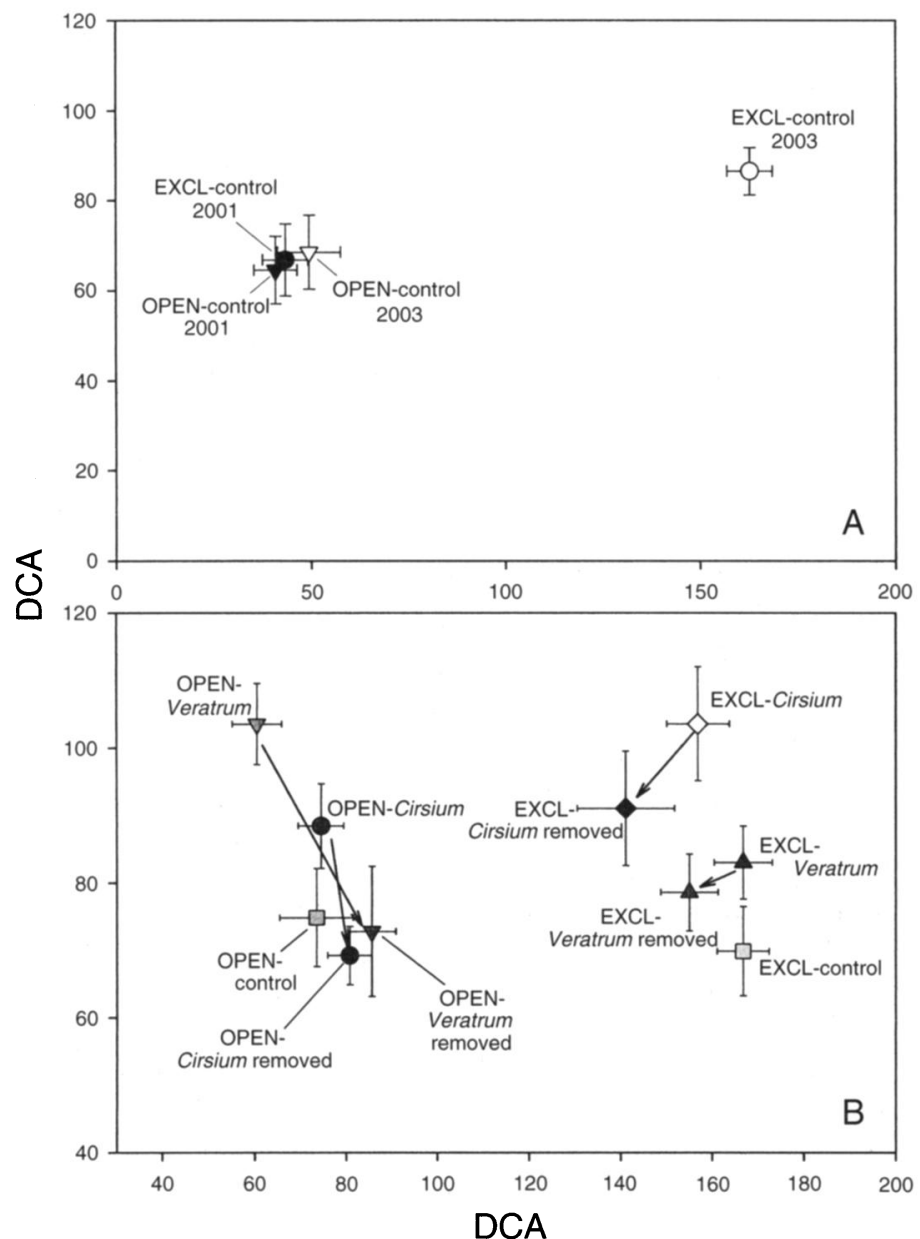

FIG. 1. Detrended correspondence analysis (DCA) for the effects of Cirsium and Veratrum inside and outside livestock exclosures. Symbols represent the means of 30-50 plots, and bars represent $95 \%$ confidence intervals as calculated in SigmaPlot (SPPS 2001). Symbols are different shapes and shades for visibility. (A) Community composition inside vs. outside exclosures immediately after establishment (2001) and two years after establishment (2003), depicting general exclosure effects. (B) Community composition contrasted among all treatment plots in 2003. Symbols labeled "control" represent plots in the open meadow, whereas other symbols are labeled for intact or experimentally removed Cirsium and Veratrum. Controls and removals for a species share a symbol shape. Arrows depict shifts in permanent plots over time. The DCA was performed with the default status and without downweighting rare species. The eigenvalues were 0.68 for the $x$-axis and 0.24 for the $y$-axis.
$=120$ individuals for each of the four target species), and monitored their survival and growth. Two species were chosen because they are considered to be palatable in the region (Grossheim 1952) and are often associated with Cirsium and Veratrum in grazed conditions (Anthoxanthum odoratum and Phleum alpinum), and two other species were chosen because they are considered to be unpalatable (Luzula pseudosudetica and Alchemilla retinervis). Small individuals of these species were transplanted into each of the three treatments in the exclosure and outside of the exclosure in May 2001 and survival and growth was measured in August 2002. Transplants were collected in the field immediately after snowmelt and randomly assigned to a treatment. We used only small plants, those with fewer than 15 leaves, and growth was measured as the proportional change in leaf number. We predicted that the performance of the palatable species would be unaffected by Cirsium and Veratrum inside exclosures, but outside exclosures we predicted that Cirsium and Veratrum will have significant positive effects on these species. In contrast, we predicted that the two unpalatable test plants (Luzula spicata and Lerchenfeldia caespitosa) would not be positively affected by Cirsium and Veratrum either inside or outside of exclosures. We statistically analyzed each transplant species separately using two-way ANOVAs in which exclosure and unpalatable neighbor were fixed effects. Because their effects were similar, to increase statistical power Cirsium and Veratrum were combined in these analyses.

\section{RESUlts}

After three growing seasons, excluding livestock at Jvari caused large changes in plant community composition associated with both unpalatable invaders and in the open (Fig. 1). Large differences between the communities associated with Cirsium and Veratrum inside and outside the Jvari exclosure indicate that grazing may affect even the species that are protected by these unpalatable invaders. In the open, permanent plot composition did not change significantly between 2001 and 2003 (Fig. 1A). However, over the same three-year period community composition in the permanent plots inside the exclosure changed dramatically. After three years, we found 18 new species inside the exclosure, an increase in richness from 35 to 53 . But outside the 


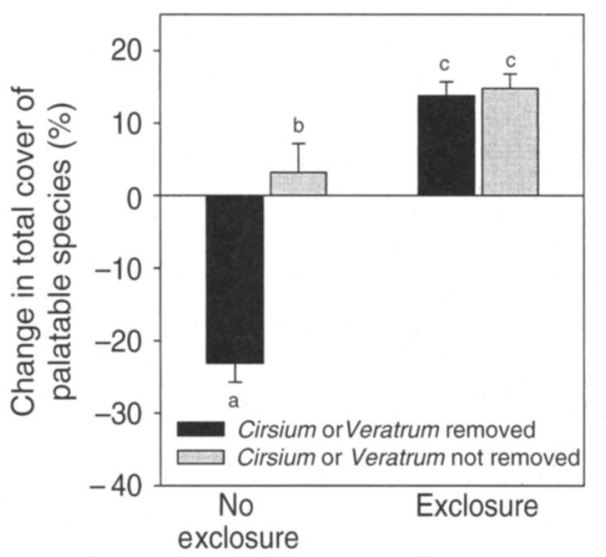

FIG. 2. Percentage change in the percent cover of palatable species in plots with Cirsium/Veratrum (the species are combined for clarity) intact or removed, inside and outside of the livestock exclosure. Error bars show \pm SE, and shared letters represent means that were not significantly different in a post-ANOVA Tukey test $(P<0.01)$.

exclosure the permanent plots totaled 34 species in 2001 and 32 in 2003.

Based upon the substantial difference in the placement of the groups along the $x$-axis in Fig. 1B, the exclosure caused far greater shifts in community composition than any other factor. However, evidence for Cirsium and Veratrum as indirect determinants of community structure was superimposed on the exclosuredriven changes. Outside of the exclosure, communities beneath Cirsium and Veratrum were different, based upon the lack of overlap between the confidence intervals and the means of treatments, than those in the open pasture matrix between these unpalatable invaders (Fig. 1B). However, when Cirsium and Veratrum were removed, the composition of the communities once associated with these unpalatable species shifted strongly toward that of the open meadow. This shift was large enough that removal communities and open matrix communities were not statistically different, based on overlap of $95 \%$ confidence intervals of removal treatments with the means of the control treatment. Cirsium and Veratrum-associated communities inside the exclosure remained different than the open matrix communities, but removal of these unpalatable species did not shift communities back toward the open matrix. In fact, the composition of removal communities shifted significantly in the direction of the open plots outside of the exclosure.

The shift in community composition inside the exclosure appeared to be driven by increases in the abundances of palatable species inside the exclosure. Eleven of the 17 significant indicator species (the species most responsible for differences in exclosure vs. non-exclosure plots derived from PC-ORD, McCune and Mefford 1997) for communities inside the exclosure are classified as palatable for livestock (Grossheim 1952). In contrast, only two of the 20 significant indicator species for communities of the open pasture were classified as palatable. In an analysis of all species identified by Grossheim (1952) as palatable combined, outside of the exclosure percent cover (estimated by giving each Braun-Blanquet class measurement the mean of the percent cover for each class) of palatable species declined by $>20 \%$ when Cirsium or Veratrum was removed, but inside the exclosure palatable species increased in cover regardless of whether or not Cirsium or Veratrum were removed (Fig. 2).

Cirsium and Veratrum also had strikingly different effects on community richness inside and outside of the exclosure (Fig. 3). Outside of the exclosure, species richness was higher under the unpalatable invaders than in the surrounding open matrix. Removing Cirsium and Veratrum resulted in a significant decrease in richness. Inside of the exclosure, Cirsium and Veratrum had no significant effect on community richness as predicted, and removal of the invaders significantly increased community richness indicating that in the absence of intense grazing the strongest effects of these species are competitive.

Experiments with transplanted palatable (Anthoxanthum odoratum and Phleum alpinum) and unpalatable (Luzula pseudosudetica and Alchemilla retinervis) species at the Gudauri exclosure corroborated the general community effects of removal and exclosures at Jvari, but not completely. Palatable species grew larger inside the exclosures (Fig. 4, for Anthoxanthum, exclosure, $F=59.93, \mathrm{df}=1,68, P<0.001$; for Phleum, exclosure, $F=13.02$, df $=1,65, P<0.001$ ), and in the exclosures Cirsium and Veratrum (combined to

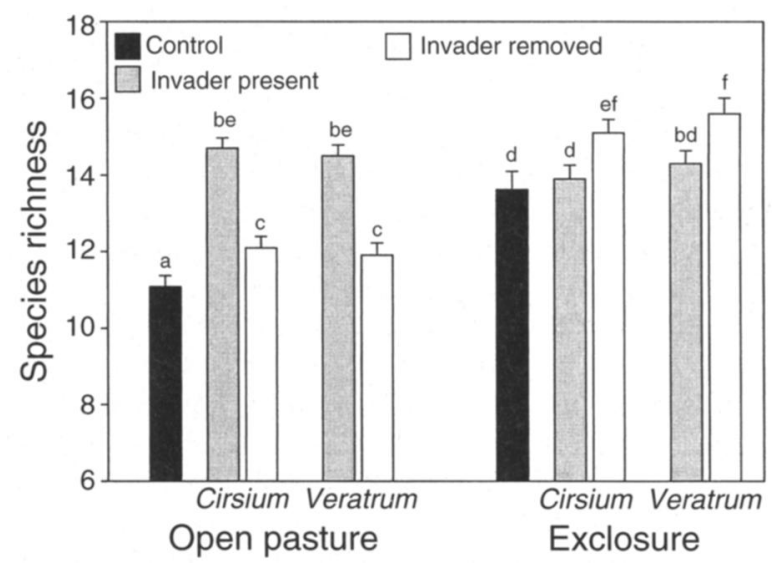

FIG. 3. Species richness associated with intact and experimentally removed Cirsium and Veratrum inside and outside the Jvari exclosure. Error bars represent + SE. In a twoway ANOVA with exclosure and removal-presence of an unpalatable neighbor as fixed effects (Cirsium and Veratrum were not different in preliminary analyses and were combined), exclosure $F=21.025$, df $=1,419, P<0.0001$; unpalatable neighbor $F=12.630$, df $=1,419, P<0.0001$; and exclosure $\times$ unpalatable neighbor $F=34.837$, df $=2$, $419, P<0.0001)$. Shared letters represent means that were not significantly different $(P<0.05)$ in a post-ANOVA Tukey test. 


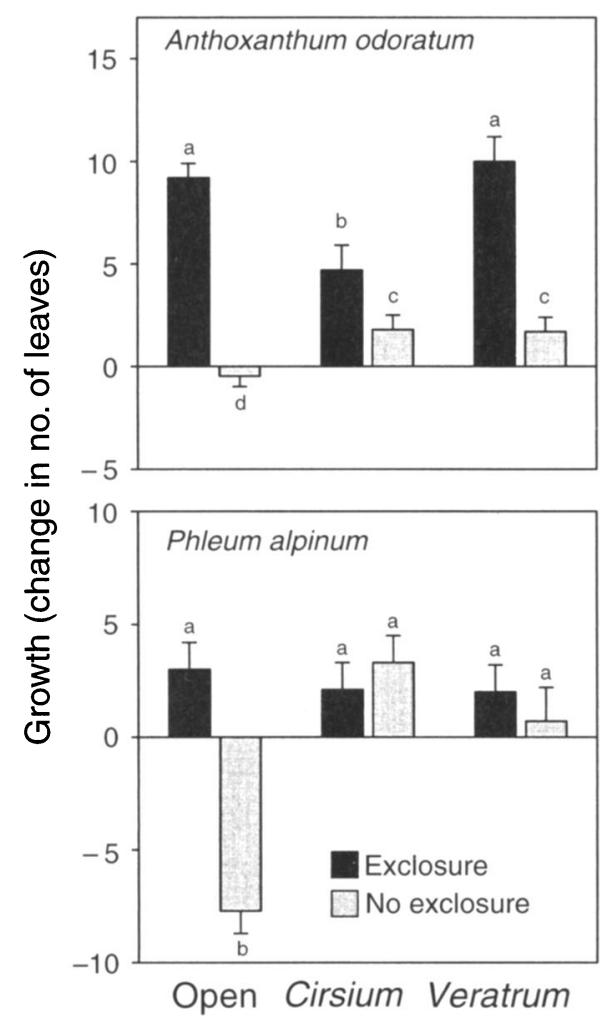

FIG. 4. Growth of two palatable (Grossheim 1952) species inside and outside of the exclosure at Gudauri and with and without Cirsium and Veratrum. Growth was measured as change in leaf number between May 2001 and August 2002. Error bars show $\pm \mathrm{SE}$, and statistics are presented in the $R e$ sults. Shared letters represent means that were not significantly different $(P<0.05)$ in a post-ANOVA Tukey test.

simplify the analysis) had no effect on the growth of the palatable species. In fact the general trend was a competitive effect of Cirsium and Veratrum on these two palatable species. However, outside of the exclosures, Cirsium and Veratrum had strong positive effects on the growth of A. odoratum and $P$. alpinum (exclosure $\times$ unpalatable neighbor, $F=4.04, \mathrm{df}=1,68, P$ $=0.009$, and $F=11.53$, df $=1,65, P<0.001$ for Anthoxanthum and Phleum, respectively. A. odoratum was highly palatable (in the whole-community measurements at Jvari it only occurred naturally inside the exclosure) and of all species it showed the most dramatic increase in the community exclosure treatment (from 0 to $\sim 15 \%$ cover). Outside of the exclosure at Jvari, where we measured community responses, the average abundance score for Phleum alpinum was 1.1 in the open, 3.7 under Cirsium, and 1.6 where Cirsium had been removed (a decrease of $45.1 \%$ ), indicating a strong facilitative effect of Cirsium. Inside of the exclosure, however, the mean score for $P$. alpinum was 2.5 in the open, 2.2 under Cirsium, and 2.1 where Cirsium had been removed (an increase of $3.3 \%$ ), (ANOVA, Cirsium $\times$ exclosure, $F=3.08, \mathrm{df}=1,158$, $P=0.019)$. The absence of a Cirsium effect in the exclosure indicates that its facilitative effect on $P$. alpinum was indirect, i.e., mediated by repulsion of herbivores by Cirsium and Veratrum.

The results for $L$. pseudosudetica and A. retinervis were not as clearcut (Fig. 5). L. pseudosudetica responded as predicted based upon its classification by Grossheim (1952) as unpalatable and its spatial disassociation with Cirsium and Veratrum measured in our earlier study (Callaway et al. 2000). The exclosure decreased the growth of $L$. pseudosudetica (exclosure, $F=3.619$, df $=1,69, P=0.029)$, and Cirsium and Veratrum had no overall effect (for both species combined, unpalatable neighbor, $F=0.076, \mathrm{df}=1,69, P$ $=0.926$ ), but inside exclosures Cirsium and Veratrum had competitive effects on $L$. pseudosudetica (exclosure $\times$ unpalatable neighbor, $F=3.072$, df $=2,69$, $P=0.053)$. L. pseudosudetica was only found at very small amounts in the exclosure at Jvari, and thus we could not match a whole-community scale response to our experimental result. Contrary to our prediction based on its classification as unpalatable, Alchemilla retinervis was not affected by the exclosure across neighbor treatments (exclosure, $F=0.087$, df $=1,66$,

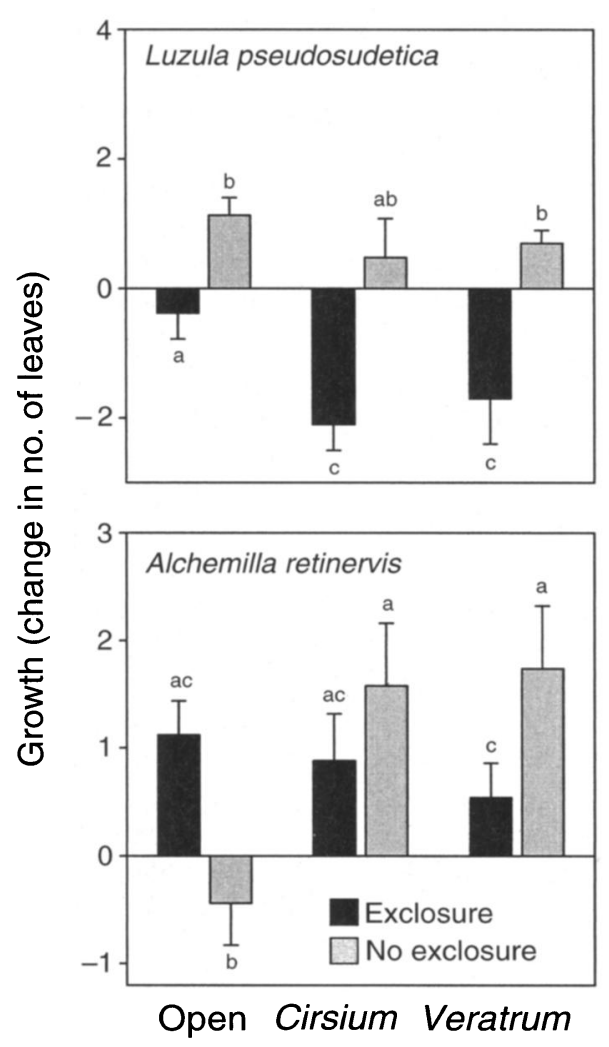

FIG. 5. Growth of two unpalatable (Grossheim 1952) species inside and outside of the exclosure at Gudauri and with and without Cirsium and Veratrum. Growth was measured as change in leaf number between May 2001 and August 2002. Error bars show $\pm \mathrm{SE}$, and statistics are presented in the $R e$ sults. Shared letters represent means that were not significantly different $(P<0.05)$ in a post-ANOVA Tukey test. 
$P=0.769$ ), nor by unpalatable neighbors (for both species combined, unpalatable neighbor, $F=2.360$, df $=1,66, P=0.102$ ). However, outside of the exclosure, Cirsium and Veratrum had strong facilitative effects on the growth of $A$. retinervis (exclosure $\times$ unpalatable neighbor, $F=5.364$, df $=2,66, P=0.007)$. Alchemilla retinervis decreased in cover by $27 \%$ when Cirsium was removed outside the exclosure, and increased in cover by $18 \%$ when Cirsium was removed inside the exclosure.

\section{Discussion}

The most salient finding of our study was that two unpalatable invaders provided strong indirect facilitative effects in heavily grazed alpine pastures. This facilitative effect was manifest for individual target species and at the community scale, driving shifts in composition and diversity. Cirsium and Veratrum, which are undesirable rangeland weeds, may in fact play an important role in maintaining species and functional diversity of overgrazed plant communities in the Caucasus. We suggest that the general phenomenon of herbivore-driven increases in Cirsium and Veratrum may preserve community structure at much larger scales by reducing the impact of grazers across landscapes (see McNaughton 1978). As argued by Milchunas and NoyMeir (2002), populations within refuges may serve as "sources" for "sink" populations that are not able by themselves to persist under grazing. Eliminating these natural grazing refuges without reducing grazing intensity may in fact do substantial long-term damage to the ecological integrity of the grazed ecosystems.

While few studies have explored facilitative effects of unpalatable species on whole community composition and diversity, many other studies have demonstrated that plants can facilitate particular neighbors by protecting them from herbivores. For example, Rousset and Lepart (2000) showed that shrubs had important indirect effects on Quercus humilis in grazed pastures in southern France. In one month, sheep grazing caused $44 \%$ mortality of $Q$. humilis seedlings in uncaged areas outside of shrubs compared to $1 \%$ under shrubs. Olff et al. (1999) described the role of thorny shrubs as indirect facilitators of tree seedlings in floodplain woodlands throughout western Europe. These indirect interactions and direct competitive interactions that develop as trees mature appear to contribute to a shifting landscape mosaic of grasslands, shrublands, and woodlands (also see Callaway and Davis 1993). In northern Sweden, Hjältén et al. (1993) experimentally exposed branches of Betula pubescens, a less-preferred browse species, to moose herbivory either alone, or mixed with highly preferred species, Sorbus aucuparia or Populus tremuloides. They found that Betula experienced higher herbivory from moose when associated with these plants of higher palatability. In contrast, Betula experienced lower rates of moose herbivory when mixed with Alnus incana, a species of lower palatability. In later experiments, Hjältén and Price (1997) transplanted potted Salix lasiolepis clones into "matrix" conspecific plants of different palatability in the field. They found that sawfly densities on the potted clones correlated significantly with the estimated palatability of the matrix plant. In other words, Salix clones appeared to benefit from reduced sawfly attacks if they were near other plants that were not as attractive to the herbivore. Hambäck et al. (2000) compared herbivory intensity on potted Lythrum inside of Myrica patches to that on potted plants outside the patches. At peak abundances of beetle herbivores the potted Lythrum outside Myrica patches held approximately 14 times the number of adult beetles, and far more eggs and larvae, than Lythrum inside Myrica patches. Not only did the herbivore populations suffer inside Myrica, the effects of the beetle herbivores on Lythrum decreased as well. The proportions of leaf and meristem damage were highly reduced and the number of flowers, fruits per plant, and seeds per plant were much higher on potted Lythrum inside Myrica thickets than outside.

In one of the few studies of how well-defended plants can indirectly affect community characteristics, Rebollo et al. (2002) found that Opuntia polycantha provides refugia from cattle grazing in the shortgrass steppe of Colorado. The dominant grass Bouteloua gracilis doubled seedhead production in Opuntia clumps in grazed treatments. However, when grazers were not present Opuntia had no effect on Bouteloua. Rebollo et al. (2002) found that Opuntia increased community diversity, but unlike the effects of Cirsium and Veratrum in the Caucasus, this increase was due to greater evenness and not greater richness. We found much stronger effects of exclosures and nurse plants communities in the Caucasus than in North American shortgrass steppe. This may be due to inherently greater responses to grazing in subhumid conditions (Milchunas et al. 1988, 1989) or more intense grazing pressure in the Caucasus. Rebollo et al. (2002) estimated 30$40 \%$ of plant production was removed by large grazers in their system. We did not measure this in the Caucasus, but total biomass was seven times higher in exclosures than outside of exclosures after one year. Our observations (R. M. Callaway) of nearby ungrazed hay meadows also indicate that far more biomass is grazed in our system. Another possible reason for the difference in our finding and that of Rebollo et al. may be soil nutrient status. Infertile pastures such as ours, especially those with low available $\mathrm{P}$ and $\mathrm{K}$, are often higher in plant species richness than fertile pastures (Tracy and Sanderson 2000) and indirect facilitative effects may be more important in species-rich systems.

In addition to our evidence for herbivory as a cause of the facilitative effects of Cirsium and Veratrum, strong associations between plant community composition and Cirsium and Veratrum canopies remained even three growing seasons after removal. This suggests that these species may also have direct effects on 
the soil, such as adding nutrients or changing microbial communities. However, it is also possible that these associations are simply the legacy of the herbivore effect that did not disappear in two growing seasons.

Cirsium and Veratrum, which superficially appear to be undesirable rangeland weeds, appear to play an important role in maintaining species and functional diversity of overgrazed plant communities in the Caucasus. Our research contributes to the growing body of literature demonstrating that plant species can have strong interdependent relationships with other plants (Bertness and Callaway 1994, Callaway 1995, 1997, Bruno et al. 2003). These interdependent interactions are not consistent with a strict individualistic perception of plant community organization (see Lortie et al. 2004). By explicitly recognizing the balance between independence and interdependence among plant species within communities we may better understand how they resist natural and anthropogenic disturbance (Callaway et al. 2002, Milchunas and Noy-Meir 2002, Lortie et al. 2004).

\section{ACKNOWLEDGMENTS}

We gratefully acknowledge the Civilian Research Development Foundation and the National Science Foundation for funding.

\section{Literature Cited}

Atsatt, P. R., and D. O'Dowd. 1976. Plant defense guilds. Science 193:24-29.

Barbour, M. G., J. H. Burk, W. D. Pitts, G. S. Gilliam, and M. W. Schwartz. 1999. Terrestrial plant ecology. Benjamin/ Cummings, Menlo Park, California, USA.

Bertness, M. D., and R. Callaway. 1994. Positive interactions in communities. Trends in Ecology and Evolution 9:191193.

Brown, B. J., and J. J. Ewel. 1987. Herbivory in complex and simple tropical successional ecosystems. Ecology 68: $108-116$.

Bruno, J. F., J. J. Stachowicz, and M. D. Bertness. 2003. Inclusion of facilitation into ecological theory. Trends in Ecology and Evolution 18:119-125.

Callaway, R. M. 1992. Effect of shrubs on recruitment of Quercus douglasii and Quercus lobata in California. Ecology 73:2118-2128.

Callaway, R. M. 1995. Positive interactions among plants. Botanical Review 61:306-349.

Callaway, R. M. 1997. Positive interactions in plant communities and the individualistic-continuum concept. Oecologia 112: 143-149.

Callaway, R. M., et al. 2002. Positive interactions among alpine plants increase with stress. Nature 417:844-848.

Callaway, R. M., and F. W. Davis. 1993. Vegetation dynamics, fire, and the physical environment in coastal vegetation of central California. Ecology 74:1567-1578.

Callaway, R. M., D. Kikodze, and Z. Kikvidze. 2000. Facilitation by unpalatable weeds may conserve plant diversity in overgrazed meadows in the Caucasus Mountains. Oikos 89:275-282.

Canfield, R. H. 1948. Perennial grass composition as an indicator of condition of southwestern mixed grass ranges. Ecology 29:190-204.

Clements, F. E. 1934. The relict method in dynamic ecology. Journal of Ecology 22:39-68.
Grossheim, A. A. 1952. Vegetation resources of the Caucasus. [In Russian.] MOIP Publications, Moscow, Russia.

Hambäck, P. A., J. Ågren, and L. Ericson. 2000. Associational resistance: insect damage to purple loosestrife reduced in thickets of sweet gale. Ecology 81:1784-1794.

Hjältén, J., K. Danell, and P. Lundberg. 1993. Herbivore avoidance by association: vole and hare utilization of woody plants. Oikos 68:125-131.

Hjältén, J., and P. W. Price. 1997. Can plants gain protection from herbivory by association with unpalatable neighbors?: a field experiment in a willow-sawfly system. Oikos 78: 317-322.

Lortie, C. J., R. W. Brooker, P. Choler, Z. Kikvidze, R. Michalet, F. I. Pugnaire, and R. M. Callaway. 2004. Rethinking plant community theory. Oikos 107:433-438.

McAuliffe, J. R. 1986. Herbivore-limited establishment of a Sonoran Desert tree: Cercidium microphyllum. Ecology 67: 276-280.

McCune, B., and M. J. Mefford. 1997. PC-ORD. Multivariate analysis of ecological data. Version 3.0. MjM Software Design, Gleneden Beach, Oregon, USA.

McNaughton, S. J. 1978. Serengeti ungulates: feeding selectivity influences the effectiveness of plant defense guilds. Science 199:806-807.

McPherson, G. R., and H. A. Wright. 1990. Effects of cattle grazing and Juniperus pinchotti canopy cover on herb cover and production in western Texas. American Midlands Naturalist 123:144-151.

Milchunas, D. G., W. K. Lauenroth, P. L. Chapman, and M. K. Kazempour. 1989. Effects of grazing, topography, and precipitation on the structure of a semiarid grassland. Vegetatio 80: 1 1-23.

Milchunas, D. G., W. K. Lauenroth, and O. E. Sala. 1988. A generalized model of the effects of grazing by large herbivores on grassland community structure. American Naturalist 132:87-106.

Milchunas, D. G., and I. Noy-Meir. 2002. Grazing refuges, external avoidance of herbivory and plant diversity. Oikos 99:113-130.

Olff, H., F. W. M. Vera, J. Bokdam, E. S. Bakker, J. M. Gleichman, K. de Maeyer, and R. Smit. 1999. Shifting mosaics in grazed woodlands driven by alternation of plant facilitation and competition. Plant Biology 1:127-137.

Rausher, M. D. 1981. The effect of native vegetation on the susceptibility of Aristolochia reticulata (Aristolochiaceae) to herbivore attack. Ecology 62:1187-1195.

Rebollo, S., D. G. Milchunas, I. Noy-Meir, and P. L. Chapman. 2002. The role of a spiny plant refuge in structuring grazed shortgrass steppe plant communities. Oikos 98:5364.

Rousset, O., and J. Lepart. 2000. Positive and negative interactions at different life stages of a colonizing species. Journal of Ecology 88:401-412.

Schaffner, U., D. Kleijn, V. Brown, and H. Müller-Schärer. 2001. Veratrum album in montane grasslands: a model system for implementing biological control in land management practices for high biodiversity habitats. Biocontrol News and Information 22:19-28.

Sims, P. L., and P. G. Risser. 2000. Grasslands. Pages 323356 in M. G. Barbour and D. Billings, editors. North American terrestrial vegetation. Cambridge University Press, Cambridge, UK.

SPSS. 2001. SigmaPlot. Version 7.101. SPSS, Chicago, Illinois, USA.

Tracy, B. F., and M. A. Sanderson. 2000. Patterns of plant species richness in pasture lands of the northeast United States. Plant Ecology 149:169-180.

Weaver, J. E., and F. W. Albertson. 1956. Grasslands of the Great Plains. Johnsen Publishing, Lincoln, Nebraska, USA. 